\title{
Zirconium oxide ceramic foam: a promising supporting biomaterial for massive production of glial cell line-derived neurotrophic factor"
}

\author{
Zhong-wei LIU ${ }^{\dagger \S 1}$, Wen-qiang $\mathrm{LI}^{\S 2}$, Jun-kui WANG ${ }^{1}$, Xian-cang MA³ ${ }^{3}$, Chen LIANG ${ }^{4}$, \\ Peng $\mathrm{LIU}^{5}$, Zheng $\mathrm{CHU}^{5}$, Yong-hui DANG ${ }^{\dagger 5,6,7}$ \\ ( ${ }^{1}$ Department of Cardiology, the Third Affiliated Hospital of Xi'an Jiaotong University, Xi' an 710068, China) \\ $\left({ }^{2}\right.$ School of Astronautics, Northwestern Polytechnic University, Xi'an 710072, China) \\ ( ${ }^{3}$ Department of Psychiatry, the First Affiliated Hospital of Xi'an Jiaotong University, Xi'an 710061, China) \\ ( ${ }^{4}$ Department of Neurosurgery, the First Affiliated Hospital of Xi'an Jiaotong University, Xi'an 710061, China) \\ $\left({ }^{5}\right.$ College of Medicine \& Forensics, Xi'an Jiaotong University Health Science Center, Xi'an 710061, China) \\ ( ${ }^{6}$ Key Laboratory of the Health Ministry for Forensic Medicine, Health Science Center, Xi'an Jiaotong University, Xi'an 710061, China) \\ ( ${ }^{7}$ MOE Key Laboratory of Environment and Genes Related to Diseases, Health Science Center, Xi'an Jiaotong University, Xi'an 710061 , China) \\ ${ }^{\dagger}$ E-mail: liuzhongweicn@gmail.com; psydyh@mail.xjtu.edu.cn \\ Received June 12, 2014; Revision accepted Oct. 9, 2014; Crosschecked Nov. 17, 2014
}

\begin{abstract}
This study investigated the potential application of a zirconium oxide $\left(\mathrm{ZrO}_{2}\right)$ ceramic foam culturing system to the production of glial cell line-derived neurotrophic factor (GDNF). Three sets of $\mathrm{ZrO}_{2}$ ceramic foams with different pore densities of 10, 20, and 30 pores per linear inch (PPI) were prepared to support a 3D culturing system. After primary astrocytes were cultured in these systems, production yields of GDNF were evaluated. The biomaterial biocompatibility, cell proliferation and activation of cellular signaling pathways in GDNF synthesis and secretion in the culturing systems were also assessed and compared with a conventional culturing system. In this study, we found that the $\mathrm{ZrO}_{2}$ ceramic foam culturing system was biocompatible, using which the GDNF yields were elevated and sustained by stimulated cell proliferation and activation of signaling pathways in astrocytes cultured in the system. In conclusion, the $\mathrm{ZrO}_{2}$ ceramic foam is promising for the development of a GDNF mass production device for Parkinson's disease treatment.
\end{abstract}

Key words: Zirconium oxide, Ceramic foam, Glial cell line-derived neurotrophic factor (GDNF), Parkinson's disease doi: 10.1631 jzus.B1400163

Document code: A

CLC number: Q819

\section{Introduction}

Parkinson's disease (PD) is one of the most common chronic diseases of nervous system in the middle-aged and elderly population (Sale et al., 2013). Caused by dopaminergic neurons degeneration in

\footnotetext{
Corresponding author

$\S$ The two authors contributed equally to this work

" Project supported by the National Natural Science Foundation of China (Nos. 81171262 and 81371473)

(ib ORCID: Zhong-wei LIU, http://orcid.org/0000-0002-3232-7863

(c) Zhejiang University and Springer-Verlag Berlin Heidelberg 2014
}

nigrostriatal system, PD is clinically characterized by static tremor, muscle rigidity, bradykinesia, and hysteresis, lowering the life quality of PD patients (Tokutake et al., 2014). Currently, the treatment effects of PD are unsatisfactory and methods are limited to oral administration of L-dopa, stereotaxic surgeries, and even fetal nigral cell transplantation (Foltynie and Kahan, 2013). However, several clinical trials indicated the inefficacy of the listed therapies evidenced by delayed dyskinesia and insufficient functional recovery in some patients (Zesiewicz et al., 2007). Therefore, it is necessary and significant to explore alternative therapies. 
Glial cell line-derived neurotrophic factor (GDNF) was categorized as a member of a transforming growth factor- $\beta$ (TGF- $\beta$ ) superfamily (Nielsen et al., 2009). Previous studies identified GDNF as a strong neuroprotectant because GDNF promoted the development, growth, survival, and maturation of various neurons in the nervous system including the central nervous system (CNS) and the peripheral nervous system (PNS) (Minnich et al., 2010; Ortiz-Ortiz et al., 2011). Pre-clinical studies confirmed curative effects of GDNF therapy in the treatment of traumatic brain injury, spinal cord injury, amyotrophic lateral sclerosis, and so on (Grundström et al., 2000; Bakshi et al., 2006; Lo et al., 2008). Moreover, Burke (2006) found that GDNF promoted survival, differentiation, and repairing of nigrostriatal dopamine neurons. Hebb et al. (2003) and Hidalgo-Figueroa et al. (2012) demonstrated that GDNF was potent in attenuating nigrostriatal damage, and thus improved motor symptoms in animal models of PD. In some clinical trials, by intraputaminal infusion, GDNF was administered to PD patients (Patel et al., 2005). Accumulating results showed improved outcomes without significant side effects (Lang et al., 2006). Hence, mass production of GDNF is of potential pharmaceutical value in PD treatment.

Astrocyte is the applicable candidate cell secreting GDNF in vitro mainly through activating signaling transducers including protein kinase $\mathrm{C} \alpha(\mathrm{PKC} \alpha)$ (Matsushita et al., 2008) and cyclic adenosine monophosphate (AMP) responsive element-binding protein (CREB) (Hisaoka et al., 2008). Compared with the regular $2 \mathrm{D}$ culturing system, a $3 \mathrm{D}$ culturing system not only realizes a high cell density in a small volume, but also provides an optimistic microenvironment for cells (Li and Cui, 2014). These characteristics enable mass production of the desired factors released from the cultured cells. The physical and chemical properties of the supporting material of the 3D culturing system would impact greatly on the proliferation, differentiation, secretion, and other biological functions of the seeding cells (Zuo and Cai, 2013). In this paper, we developed a novel zirconium oxide $\left(\mathrm{ZrO}_{2}\right)$ ceramic foam as the supporting material, which was of high porosity with an open-pore structure, for astrocyte 3D culturing to yield GDNF. The biocompatibility of the material, cell proliferation, and GDNF production were also determined to evaluate its possible application in the pharmaceutical industry.

\section{Materials and methods}

\section{1 $\mathrm{ZrO}_{2}$ ceramic foam preparation}

The $\mathrm{ZrO}_{2}$ foam scaffolds were manufactured and prepared using an 'impregnation' method by Drache Umwelttechnik GmbH (Germany). The raw material, $\mathrm{ZrO}_{2}$ ceramic powder combined with the stabilizer, was mixed with the organic binder agent. The mixture was formed into a 'slurry' and absorbed by the organic sponge. Then, the sponge saturated with the slurry was sintered at $1200{ }^{\circ} \mathrm{C}$ for about $2 \mathrm{~h}$ to decompose sponge skeleton and guarantee the rigidity of the foam ligament.

\subsection{Foam physical parameter measurement}

Three sets of foam samples with different pore densities $(\omega=10,20$, and 30 pores per linear inch (PPI)) were provided by the manufacturer in this study and the nominal foam porosity was 0.90 . Some key physical parameters including foam porosity $(\varepsilon$, volume fraction of void pores), pore size $\left(d_{\mathrm{p}}\right)$, fiber diameter $\left(d_{\mathrm{f}}\right)$, volumetric interfacial area of the ligaments $\left(a_{\mathrm{if}}\right)$, and micro surface area of the material $\left(a_{\mathrm{sf}}\right)$ were determined in this study. It was difficult to measure a typical pore size for a specific pore density since the cells are randomly distributed and most cells seem to be hexagonal, pentagonal, or circular. Hence, we determine pore size and fiber diameter by calculating the arithmetic average value of five different pore sizes and fiber diameters for each foam sample to guarantee the accuracy. The interfacial area of the ligaments $\left(a_{\mathrm{if}}\right)$ is dependent on the pore size $\left(d_{\mathrm{p}}\right)$ and fiber diameter $\left(d_{\mathrm{f}}\right)$. The interfacial area of the foam structure can be calculated by $a_{\mathrm{if}}=3 \pi d_{\mathrm{f}} / d_{\mathrm{p}}^{2}$.

We characterized the micro pore structure by a nitrogen sorption experiment with manometric technique (Autosorb IQ). The sample was degassed by a vacuum molecular pump for $12 \mathrm{~h}$ at the atmospheric temperature of $473.15 \mathrm{~K}$ before the absorption. Then, the absorption procedure was completed in a liquid nitrogen atmosphere $(77 \mathrm{~K})$. The volume and the micro surface area were deduced using the BrunauerEmmett-Teller (BET) sorption theory based on the measured data.

\subsection{Primary astrocyte cell culturing and seeding}

Primary astrocytes were harvested from cerebral cortices of neonatal Sprague-Dawley (SD) rats 
(Animal Experimental Center, Xi'an Jiaotong University, China) according to the protocol described by Cho et al. (2010). The animal experimental procedures were approved and authorized (License No. 2014-O59) by the Ethics Committee of Experimental Animals in Xi'an Jiaotong University, China. After digestion, dissociated cortical cells were suspended in Dulbecco's modified Eagle medium (DMEM; Gibco) containing 10\% fetal bovine serum (FBS; Gibco), $2 \mathrm{mmol} / \mathrm{L}$ L-glutamine (Invitrogen), and $100 \mathrm{U} / \mathrm{ml}$ penicillin-streptomycin (Invitrogen). Cells were cultured in $25-\mathrm{cm}^{2}$ culture flasks (Corning). After agitation and culture medium replacement, non-astrocytic cells (neurons and microglia) were detached and removed from the culturing system. After 12-14 d cell culture, a monolayer of purified (more than 95\% purity, testified by glial fibrillary acidic protein (GFAP) staining) primary astrocytes could be acquired.

The ceramic foam scaffolds were washed by aviation kerosene and then by ethanol absolute, sterilized prior to cell seeding. The interior wall of each well in a six-well plate (Corning) was coated with Sigmacote (Sigma-Aldrich) to eliminate cell attachment to the wall. A laser cutter was used to modify the shape of the ceramic foam (cylinder with diameter of $3.5 \mathrm{~cm}$ and height of $1.5 \mathrm{~cm}$ ) to fit in the culturing wells of the six-well plate. As the diameters of the foam cylinder and the well were the same, the foam was fixed to the well by contracting the interior wall of the wells. The same amount of cells $\left(6 \times 10^{6}\right.$ cells $\left./ 20 \mathrm{ml}\right)$ was seeded to the foam scaffold with different pore densities $(10,20$, and $30 \mathrm{PPI})$ soaked in the culturing medium and to bare medium as a control in six-well plates. The culturing medium in the wells of the culturing plate was replaced every two days. The astrocytes cultured in the six-well plates were harvested by digestion. The same amount of harvested cells from each group was used for the subsequent experiments including cell viability assay, cell proliferation assay, enzyme-linked immunosorbent assay (ELISA), real-time polymerase chain reaction (PCR), and Western blotting.

\subsection{Scanning electron microscopy observation}

Samples of ceramic foams or foams with cells embedded were collected and prepared for scanning electron microscope (SEM) observation. Samples were fixed in glutaraldehyde $(2.5 \%)$ for $2 \mathrm{~h}$, then washed by distilled water, and then immersed in $\mathrm{OsO}_{4}$ (4\%) for $1 \mathrm{~h}$. After dehydration by a graded ethanol solution $(25 \%, 50 \%, 75 \%, 80 \%, 90 \%$, and $100 \%)$, the samples were dried and coated with gold-palladium by a JFC-1600 auto sputter coater (JEOL, Japan), and then observed with a TM-1000 SEM (Hitachi, Japan).

\subsection{Cell viability assay}

The biocompatibility of the ceramic foam was evaluated by MTT (3-[4,5-dimethylthiazol-2-yl]-2,5 diphenyltetrazolium bromide) assay after culturing. MTT reagent $(50 \mu \mathrm{l})$ was added to each well and incubated in $10 \% \mathrm{CO}_{2}$ at $37{ }^{\circ} \mathrm{C}$ for $4 \mathrm{~h}$. The formed crystals were dissolved in solution ( $1 \%$ Triton-X 100 and $0.01 \mathrm{~mol} / \mathrm{L} \mathrm{HCl}$ in isopropanol). The absorbance at $570 \mathrm{~nm}$ of each well was read by a plate reader (Bio-Rad). The viable cell percentage was expressed as a percentage of viable cells in each culturing system.

\subsection{Cell proliferation examination}

The proliferation of astrocytes was evaluated by DNA content assessment. DNA was extracted from all cells collected from each culturing system by using a mammalian genomic DNA extraction kit (Beyotime Biotechnology, China). The content of DNA was then determined using a Quant-iTTM PicoGreen doublestranded DNA (dsDNA) assay kit (Invitrogen). All procedures above followed the instructions of the manufacturers.

\subsection{ELISA assessment of GDNF production}

The supernatants from the astrocytes culturing system were collected for ELISA assay using a rat GDNF ELISA kit (Promega) according to the protocol provided by the manufacturer. After the absorbance was detected at $450 \mathrm{~nm}$ using a plate reader (Bio-Rad), the concentrations of GDNF in the supernatants were then calculated.

\subsection{Real-time quantitative PCR}

Total RNA was extracted from the cultured astrocytes with the RNAfast 200 kit (Fastagen), and then reverse-transcribed to complementary DNA (cDNA) with the PrimeScript RT reagent kit (TaKaRa, Japan) according to the protocols provided by the manufacturers. Real-time quantitative PCR was performed using the SYBR Premix Ex Taq ${ }^{\mathrm{TM}}$ II (TaKaRa, 
Japan) and Prism 7500 real-time detection system (Applied Bio-Systems). Oligonucleotide primers for GDNF and $\beta$-actin are listed in Table 1. Relative mRNA expression levels (normalized to $\beta$-actin) were calculated by relative cycle threshold method using Bio-Rad IQ5 software (Ver 1.0, Bio-Rad).

Table 1 Primers for real-time PCR

\begin{tabular}{ccc}
\hline $\begin{array}{l}\text { Barley } \\
\text { variety }\end{array}$ & $\begin{array}{c}\text { Primer sequence } \\
\left(5^{\prime}-3^{\prime}\right)\end{array}$ & $\begin{array}{c}\text { Size } \\
(\mathrm{bp})\end{array}$ \\
\hline $\begin{array}{c}\text { GDNF F: GACTCCAATGTGCCCGAGA } \\
\text { R: CCTACCTTGTCACTTGCTAGCC }\end{array}$ & 394 \\
$\beta$-actin F: TGGCACCCAGCACAATGAA & 186 \\
R: CTAAGTCATAGTCCGCCTAGAAGCA & \\
\hline
\end{tabular}

\subsection{Western blotting}

The same amount of cultured astrocytes $\left(6 \times 10^{6}\right)$ was lysed and homogenized in an RIPA (radioimmunoprecipitation assay) lysis buffer system with phenylmethylsulfonyl fluoride (PMSF) (Santa Cruz). The resultant supernatants were separated by centrifugation at $12500 \mathrm{~g}$ at $4{ }^{\circ} \mathrm{C}$ for $10 \mathrm{~min}$. The protein concentration in each sample was detected by the BCA protein assay kit (Santa Cruz). After subjecting to a $1 \times$ sodium dodecyl sulfate polyacrylamide gel electrophoresis (SDS-PAGE) loading buffer, sample protein was then separated by vertical electrophoresis in an SDS-polycrylamide gel (10\%). Separated protein was then transferred to a polyvinylidene fluoride (PVDF) membrane. The blots were probed by specific antibodies against the proliferating cell nuclear antigens (PCNA; 5000×; Abcam), PKC $\alpha$ (5000×; Abcam), total CREB (5000×; Cell Signaling Tech.), phospho CREB (5000×; Cell Signaling Tech.), GDNF (5000×; Abcam), and $\beta$-actin (2000×; Santa Cruz) at $4{ }^{\circ} \mathrm{C}$ for $10 \mathrm{~h}$. After being washed by Tris-buffered saline (TBS)-Tween $20(0.02 \%)$, a second antibody conjugated to horseradish peroxidase (HRP; Santa Cruz) was employed to incubate the membrane. The membranes were developed with Super Signal West Pico chemiluminsecence reagent (Thermo Scientific) and visualized on X-ray films.

\subsection{PKCa translocation evaluation}

The same amount of cells $\left(6 \times 10^{6}\right)$ from each culturing system was centrifuged, collected, and lysed.
Harvested lysates were centrifuged at $500 \mathrm{~g}$ for $10 \mathrm{~min}$, and then the supernatant was further centrifuged at $100000 \mathrm{~g}$ at $4{ }^{\circ} \mathrm{C}$ for $1 \mathrm{~h}$. The resultant supernatant was collected as a cytosolic fraction. The resultant pellet was resuspended in a protein extraction buffer, and then centrifuged at $100000 \mathrm{~g}$ for $1 \mathrm{~h}$. The resultant supernatant was collected as a membrane fraction. The translocation of PKC $\alpha$ was evaluated by the expression level of PKC $\alpha$ in the membrane fraction detected by Western blotting.

\section{Results}

\subsection{Physical parameters of $\mathrm{ZrO}_{2}$ ceramic foam}

The macrostructures and microstructures of the typical $\mathrm{ZrO}_{2}$ foams used in this study are shown in Figs. 1a and 1d. It can be observed that the foam consists of cell-like pores which are formed by innerconnected fiber ligaments. The measured and calculated results of porosity, pore size, fiber diameter, and interfacial area are listed in Table 2. The microvolume increased in linear relation with the relative pressure from 0 to 0.93 (Fig. 1b). This indicates a relative uniform pore distribution and sustainable pore characteristic for absorption (desorption). The volume encounters a dramatic increase with the pressure ratio of $0.93-1.00$. Fig. 1c shows the variation of cumulative pore volume distribution with the cell width, which shows the pore diameter ranging 2.5-10.0 nm with the maximum pore distribution at the peak size of $3.169 \mathrm{~nm}$.

\section{2 $\mathrm{ZrO}_{2}$ ceramic foam astrocyte culturing system elevated GDNF yield}

Fig. 2 shows the yields of GDNF from each astrocytes culturing system over $20 \mathrm{~d}$ starting from seeding. The productivity of GDNF increased significantly and was sustained through the $20-\mathrm{d}$ period in the ceramic foam culturing system compared with regular 2D culturing system whose GDNF productivity began to fall after 10 -d culturing. In the ceramic foam culturing system, foam with pore density of 20 PPI exhibited the highest average GDNF yield during the 20-d observation compared with that of 10 PPI and 30 PPI. 


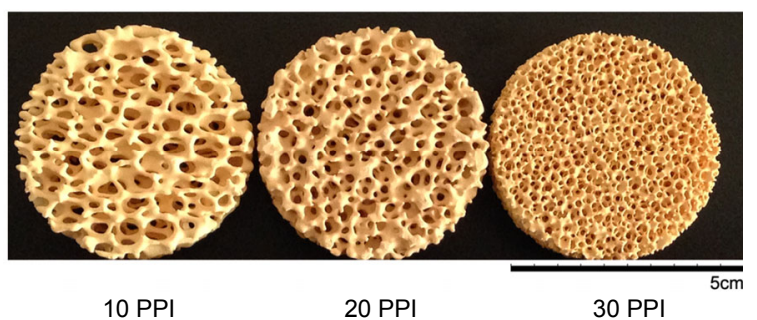

(a)

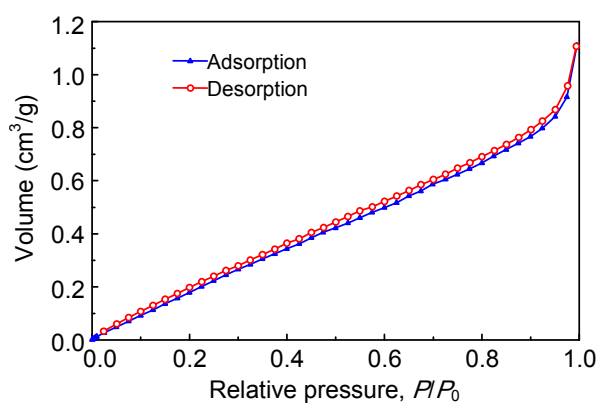

(b)

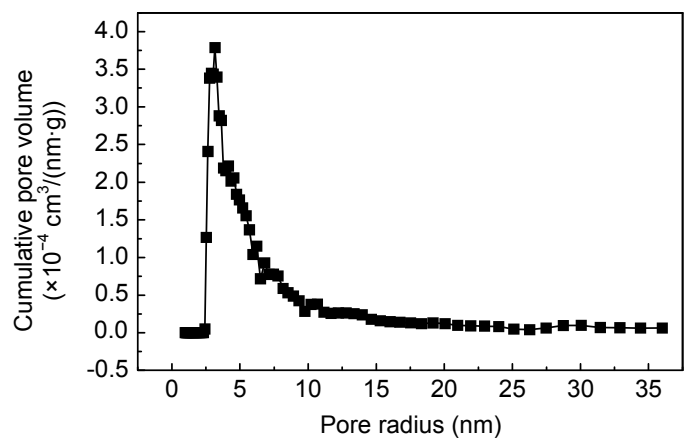

(c)
$10 \mathrm{PPI}$
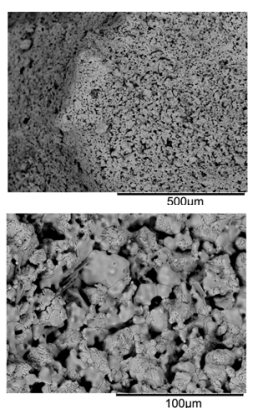

20 PPI
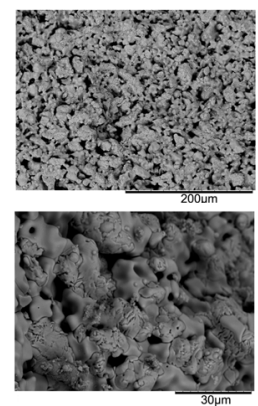

(d)
$30 \mathrm{PPI}$
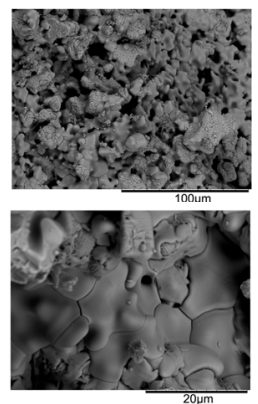

Fig. 1 Physical properties of $\mathrm{ZrO}_{2}$ ceramic foam (a) Macrostructures of $\mathrm{ZrO}_{2}$ ceramic foams with three different pore densities $(10,20$, and $30 \mathrm{PPI})$ captured by an optical camera; (b) Nitrogen absorption results of the microvolume as the function of the pressure ratio for the $\mathrm{ZrO}_{2}$ foam; (c) Variation of cumulative pore volume distribution with the cell width by using nitrogen sorption method; (d) Different magnification of fiber surfaces of $\mathrm{ZrO}_{2}$ foam captured by scanning electron microscopy
Table 2 Physical parameters of $\mathrm{ZrO}_{2}$ ceramic foam

\begin{tabular}{cccc}
\hline $\begin{array}{c}\text { Pore density } \\
(\mathrm{PPI})\end{array}$ & $\begin{array}{c}\text { Pore size } \\
\left(\mathrm{mm}^{2}\right)\end{array}$ & $\begin{array}{c}\text { Fiber diameter } \\
(\mathrm{mm})\end{array}$ & $\begin{array}{c}\text { Interfacial } \\
\text { area }\left(\mathrm{m}^{-1}\right)\end{array}$ \\
\hline 10 & 2.94 & 0.357 & 0.389 \\
20 & 1.73 & 0.029 & 0.659 \\
30 & 0.78 & 0.094 & 0.456 \\
\hline
\end{tabular}

(a)

(a) 20

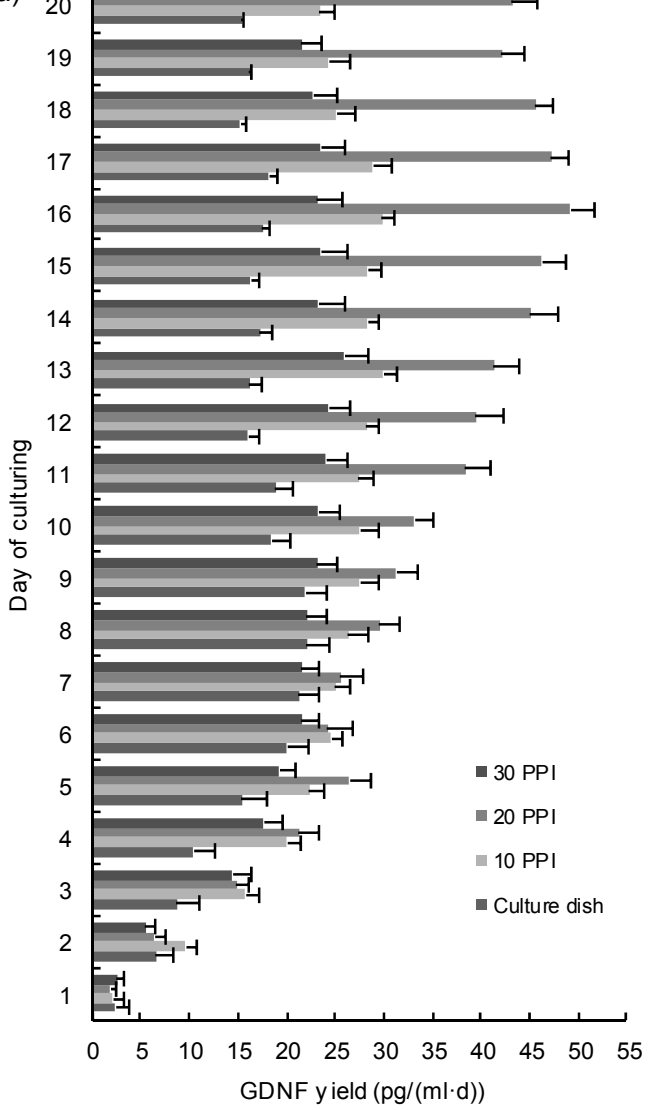

(b)

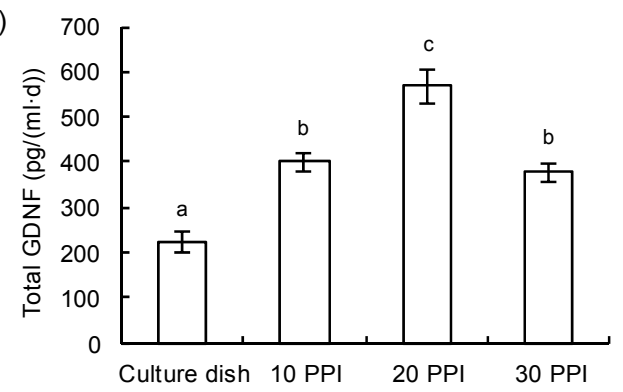

Fig. 2 GDNF productivity in $\mathrm{ZrO}_{2}$ ceramic foam astrocyte culturing system

Daily GDNF yield (a) and total production of GDNF (b) from different culturing systems including regular culture dish and $\mathrm{ZrO}_{2}$ ceramic foam $3 \mathrm{D}$ culturing systems with different pore densities $(10,20$, and 30 PPI) during the 20-d culturing. Values are presented as mean $\pm \mathrm{SD}$ with different letters above the bars showing $P<0.005$ 


\section{3 $\mathrm{ZrO}_{2}$ ceramic foam was biocompatible and en- hanced astrocytes proliferation in limited volume}

There were no significant differences of the viable cell percentage in each culturing system evidenced by MTT assay (Fig. 3a). The attachment of seeded astrocytes to ceramic foam is observed by SEM (Fig. 3b). The dsDNA content was more dramatically elevated in the ceramic foam culturing system than in the regular one (Fig. 3c). dsDNA content increased more significantly in foam with pore density of 20 PPI than of 10 PPI and 30 PPI. Additionally, the elevated expression of PCNA on Day 8 in astrocytes in the ceramic foam culturing system is shown in Fig. 4.

\section{4 $\mathrm{ZrO}_{2}$ ceramic foam cell culturing pattern stimulated synthesis and secretion of GDNF in astrocytes}

On Day 8 during culturing, at both transcriptional and translational levels, there were no significant differences of GDNF expression in the same amount of astrocytes from the ceramic foam culturing system than from the regular one (Fig. 4). Notably, in the system supported by foam, in the same amount of astrocytes from each culturing system, expression of GDNF, translocation of $\mathrm{PKC} \alpha$, and phosphorylation of CREB increased significantly in the ceramic foam culturing system compared with the regular one; this was more dramatic in the system supported by foam with pore density of $20 \mathrm{PPI}$ than of $10 \mathrm{PPI}$ and $30 \mathrm{PPI}$.

\section{Discussion}

The normal structure and function of organs in vivo are maintained by natural cell alignments, metabolism, complicated cellular interactions, and so on, which rely on the 3D structural nature of biological tissues. Biological active factors, such as cytokines and tumor antibodies, are employed in clinical treatments (Schenck et al., 2007; Elliot et al., 2008; Beohar et al., 2010; von Frenckell and Malaise, 2012). Most of these biological factors could not be acquired by artificial synthesis but through selection and purification from the products generated by specific living cells (Tanaka et al., 2008). Although these biological products could be harvested from regular 2D cell culturing system, the productivity is not

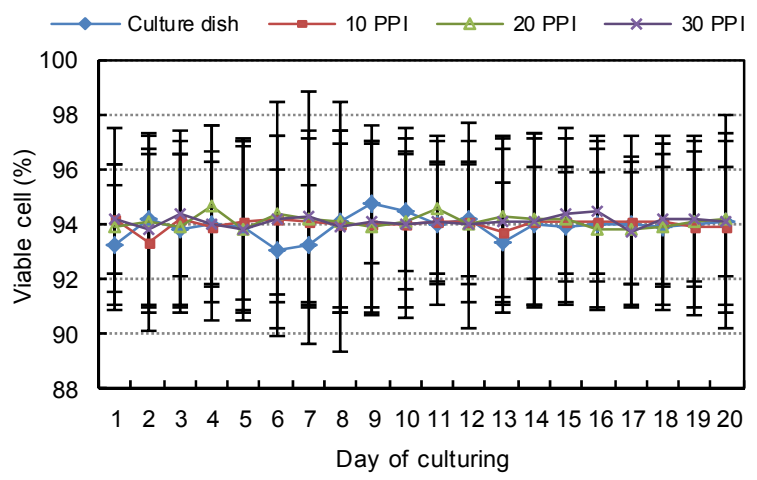

(a)
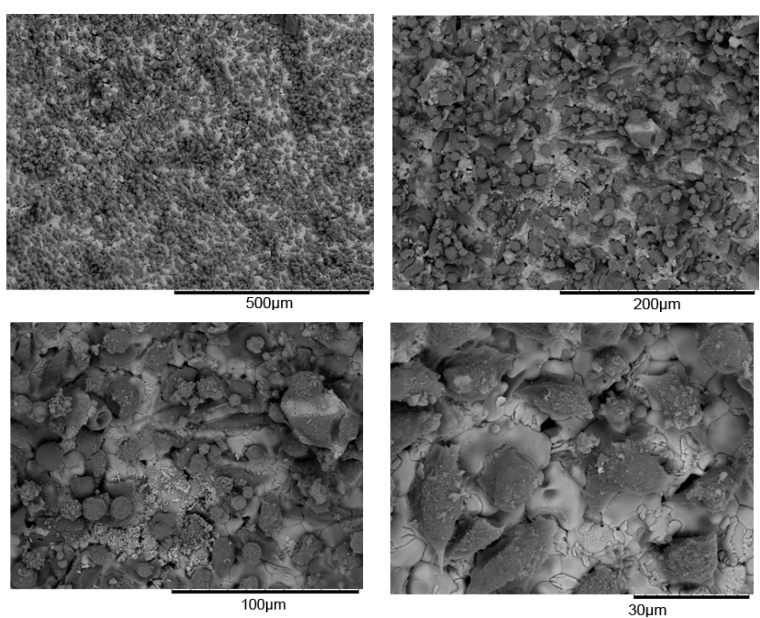

(b)

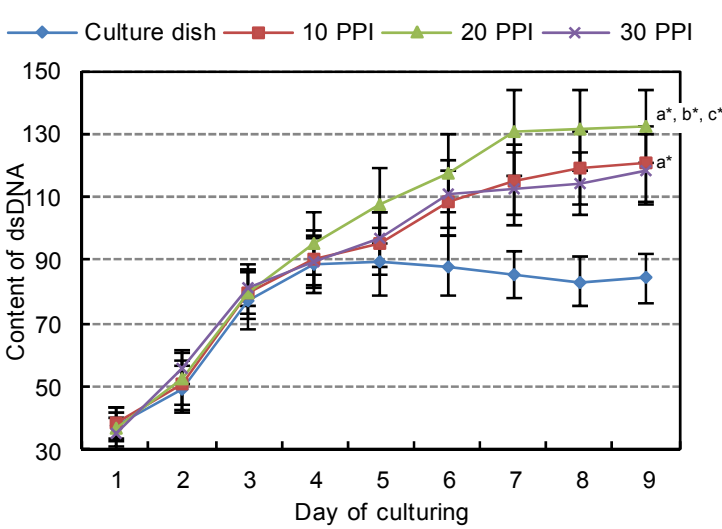

(c)

Fig. 3 Astrocytes seeded in $\mathrm{ZrO}_{2}$ ceramic foam (a) Viable cell percentages of seeded astrocytes in different culturing systems during 20-d culturing by MTT assay; (b) SEM pictures of astrocytes seeded in $\mathrm{ZrO}_{2}$ ceramic foam; (c) Content of dsDNA extracted from astrocytes seeded in different culturing systems during 20 -d culturing. a, b, and c shows values significantly different from culture dish, 10 PPI, and 30 PPI, respectively. ${ }^{*} P<0.005$ 
(a)

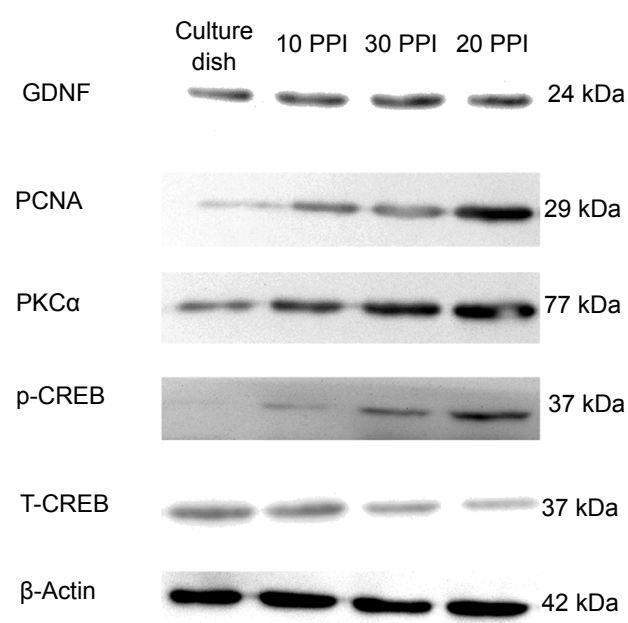

(d)

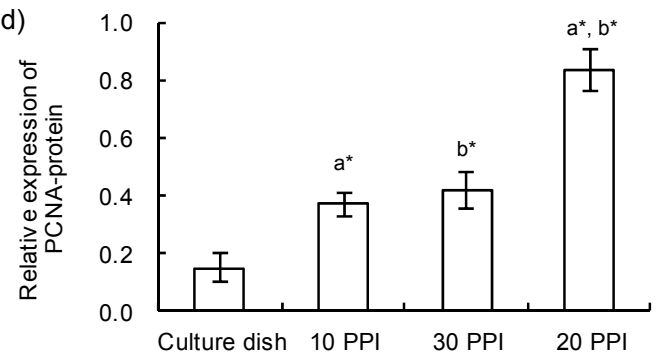

(f)

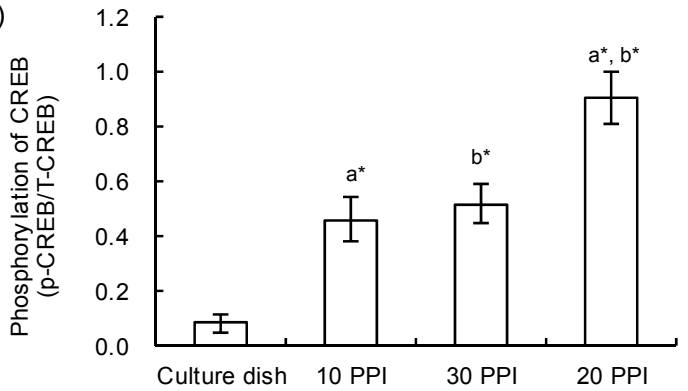

(b)

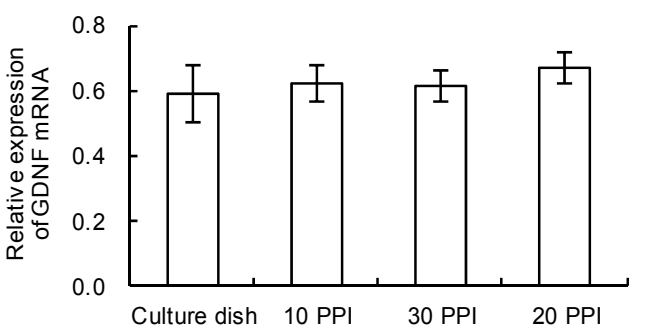

(c)

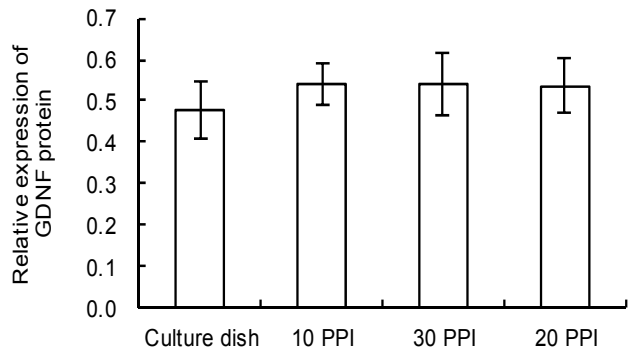

(e)

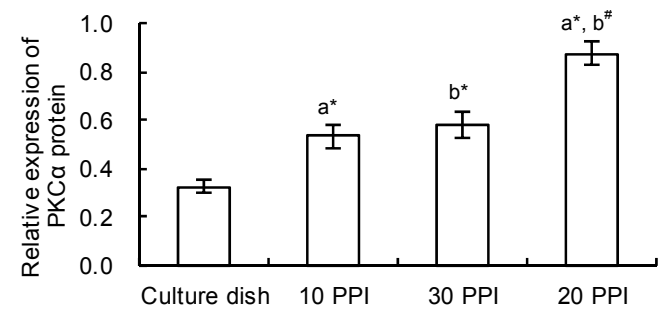

Fig. 4 Changes of expressions of molecules in seeded astrocytes on Day 8 of culturing

(a) Western blotting of GDNF, PCNA, PKC $\alpha$, p-CREB, T-CREB, and in astrocytes on Day 8 of culturing in different culturing systems: regular culture dish and $\mathrm{ZrO}_{2}$ ceramic foam $3 \mathrm{D}$ culturing systems with pore densities of 10, 20, and 30 PPI. Relative expressions of GDNF mRNA (b), GDNF protein (c), PCNA protein (d), PKC $\alpha$ protein (e), and p-CREB/T-CREB (f) in astrocytes on Day 8 of culturing in each culturing system. Values are presented as mean \pm SD. a and $b$ above the bars shows values significantly different from culture dish and 10 PPI, respectively. ${ }^{\#} P<0.01 ;{ }^{*} P<0.005$

optimistic because of the inadequacy in mimicking the in vivo culturing environment and the vulnerability to external stimuli of the $2 \mathrm{D}$ culturing system (Heckmann et al., 2008). Hence, we introduced $\mathrm{ZrO}_{2}$ ceramic foam as a scaffold to support the $3 \mathrm{D}$ cell culturing system. Primary astrocytes were cultured in this system, and the production of its final biological products, GDNF, was found to be elevated dramatically compared with the regular 2D culturing system. Mechanically, in this study, we also demonstrated that the elevation of GDNF yield was due to the favorable biocompatibility of $\mathrm{ZrO}_{2}$ ceramic foam as well as the increased proliferation and stimulated
GDNF synthesis in astrocytes seeded in the 3D culturing system.

To achieve a high efficiency, it is desirable that a generating device for biological products produces the highest possible number of cells within a limited volume. In this study, we prepared $\mathrm{ZrO}_{2}$ ceramic foams with serial pore densities of 10, 20, and $30 \mathrm{PPI}$. The interfacial specific surface areas of the foams were significantly increased by the foam fiber surfaces within the same volume, indicating that the foams could provide a higher surface area per unit volume. Scanning electronic microscopy observation of the foam showed the features of uneven topography and 
rough fiber surface, which would facilitate anchoring, adaptation, and attachment of astrocytes to this scaffold. Additionally, the cell viability assay confirmed the favorable response of primary astrocytes after being seeded to the ceramic foams. These featured characteristics of $\mathrm{ZrO}_{2}$ ceramic foam enabled it to sustain a large cell population to produce more biological products. In this study, we found that the ceramic foam with pore density of 20 PPI was more suitable for astrocytes culturing, by improving the amount of cells. Pore density is one of the determining physical parameters of ceramic foam which would affect the biological properties of cells when ceramic foams are utilized in a cell culturing system. At a given dimension, the foam with higher pore density has more available surface internal area. As the internal surface of the foam is for cell attachment, providing more space for cell growth, more cells would settle in the foam with a higher pore density. As a result, the cell proliferation is boosted. However, as the pore density increases, the flowability of the culturing medium in the ceramic foam is decreased. Thus the oxygen and nutrients in the medium could not penetrate to the deeper space in the foam. Additionally, the internal structure of the foam with high pore density is more complex which would offer obstructions or barriers for cell migration to the deeper space of the foam. As a result, a 'bare area' without cells or with few cells could exist in the foam at high pore density.

In this study, we chose astrocytes as seeding cells in the $3 \mathrm{D}$ culturing system to produce GDNF. As a member of TGF- $\beta$, GDNF was known for its neuroprotective and restorative effects on dopaminergic neurons (Sun et al., 2005; Wu et al., 2008). GDNF acts as a ligand to induce the activation of several transmembrane receptors in dopaminergic neurons such as the ligand binding component GDNF-family receptor $\alpha-1$ (GFR $\alpha 1)$. Then the down-stream signaling pathways such as mitogen-activated protein kinase pathway are activated and this determines the survival of the neurons. GDNF treatment was considered a feasible and promising treatment strategy in curing PD (Foltynie and Kahan, 2013). In an animal model of PD, both GDNF ventricular infusion and GDNF secreting cell transplantation showed positive therapeutic effects, which was evidenced by an improved behavioral score and rehabilitated dopamin- ergic neurons in 6-hydroxydopamine lesioned striatum (Shingo et al., 2002; Yasuhara et al., 2005). The achievements for GDNF clinical treatment are also encouraging since the first successful intraputaminal GDNF infusion treatments in PD patients in 2003 (Gill et al., 2003). It was reported that direct administration of GDNF into putamen in PD patients improved their unified Parkinson's disease rating scale (UPDRS) scores in the following year off medication without any serious side effects (Yasuhara et al., 2007). Remarkable functional recovery in PD patients was found in accordance with pathological changes of dopaminergic fibers sprouting in PD patients receiving GDNF infusion treatment (Gill et al., 2003; Patel et al., 2005). As the technique of cell transplantation is relatively complex and its feasibility is currently in doubt, the utility of direct intraputaminal/ intraventricular GDNF injection is the appropriate alternative strategy in curing PD. Future pharmaceutical demands of GDNF can be predicted. A device or system, such as the $3 \mathrm{D}$ astrocytes culturing system in this study, for massive production of GDNF would be of potential practical value.

The yield of GDNF in the 3D astrocyte culturing system in this study was considerable. Evidenced by increased dsDNA level and PCNA expression, the proliferation of primary astrocytes in the $\mathrm{ZrO}_{2}$ ceramic foam supported 3D culturing system was dramatically stimulated. Assuming that each single astrocyte secretes and releases an equal amount of GDNF, a larger viable cell population per unit volume should be responsible for a substantial GDNF production from the system. The optimal pore density for astroycyte proliferation was 20 PPI rather than 30 PPI or 10 PPI. The activation of several cellular signaling pathways is also responsible for GDNF production. In several previous studies, stimulated GDNF release from astrocytes was PKC $\alpha$-dependent (Matsushita et al., 2008). CREB was reported as another important activator in promoting GDNF production in cultured astrocytes (Parsadanian et al., 2006; Hisaoka et al., 2008; Golan et al., 2011). Generally, an increased PKC $\alpha$ translocation level and CREB phosphorylation level indicate the activation of PKC $\alpha$ and CREB related pathways. In the present study, notably, on Day 8 during culturing, when under the similar conditions of cell amount and GDNF productivity, significantly increased PKC $\alpha$ translocation and CREB 
phosphorylation were found in astrocytes from the 3D culturing system compared with the regular 2D one. This result indicated that the $3 \mathrm{D}$ culturing pattern stimulated GDNF generating signaling pathways in cultured astrocytes.

\section{Conclusions}

Our findings suggested that: (1) the $\mathrm{ZrO}_{2}$ ceramic foam was biocompatible when supporting primary astrocyte 3D culturing; (2) the yield of GDNF of $\mathrm{ZrO}_{2}$ ceramic foam based 3D astrocytes culturing system overwhelmed that from the regular 2D culturing system; (3) the considerable productivity of GDNF in the 3D system was due to elevation of astrocyte proliferation and the stimulation of GDNF secretion pathways from astrocytes.

\section{Compliance with ethics guidelines}

Zhong-wei LIU, Wen-qiang LI, Jun-kui WANG, Xiancang MA, Chen LIANG, Peng LIU, Zheng CHU, and Yong-hui DANG declare that they have no conflict of interest.

All institutional and national guidelines for the care and use of laboratory animals were followed.

\section{References}

Bakshi, A., Shimizu, S., Keck, C.A., et al., 2006. Neural progenitor cells engineered to secrete GDNF show enhanced survival, neuronal differentiation and improve cognitive function following traumatic brain injury. Eur. J Neurosci., 23(8):2119-2134. [doi:10.1111/j.1460-9568. 2006.04743.x]

Beohar, N., Rapp, J., Pandya, S., et al., 2010. Rebuilding the damaged heart: the potential of cytokines and growth factors in the treatment of ischemic heart disease. $J . A m$. Coll. Cardiol., 56(16):1287-1297. [doi:10.1016/j.jacc. 2010.05.039]

Burke, R.E., 2006. GDNF as a candidate striatal target-derived neurotrophic factor for the development of substantia nigra dopamine neurons. In: Riederer, P., Reichmann, H., Youdim, M.B.H., et al. (Eds.), Parkinson's Disease and Related Disorders. Springer-Verlag/Wien, p.41-45. [doi:10.1007/978-3-211-45295-0_8]

Cho, K.S., Park, S.H., Joo, S.H., et al., 2010. The effects of IL-32 on the inflammatory activation of cultured rat primary astrocytes. Biochem. Biophys. Res. Commun., 402(1):48-53. [doi:10.1016/j.bbrc.2010.09.099]

Elliot, M.J., Maini, R.N., Feldmann, M., et al., 2008. Treatment of rheumatoid arthritis with chimeric monoclonal antibodies to tumor necrosis factor $\alpha$. Arthritis Rheum., 58(S2):S92-S101. [doi:10.1002/art.23362]

Foltynie, T., Kahan, J., 2013. Parkinson's disease: an update on pathogenesis and treatment. J. Neurol., 260(5):14331440. [doi:10.1007/s00415-013-6915-1]
Gill, S.S., Patel, N.K., Hotton, G.R., et al., 2003. Direct brain infusion of glial cell line-derived neurotrophic factor in Parkinson disease. Nat. Med., 9(5):589-595. [doi:10. 1038/nm850]

Golan, M., Schreiber, G., Avissar, S., 2011. Antidepressants elevate GDNF expression and release from $\mathrm{C}_{6}$ glioma cells in a $\beta$-arrestin1-dependent, CREB interactive pathway. Int. J. Neuropsychopharmacol., 14(10):12891300. [doi:10.1017/S1461145710001550]

Grundström, E., Lindholm, D., Johansson, A., et al., 2000. GDNF but not BDNF is increased in cerebrospinal fluid in amyotrophic lateral sclerosis. NeuroReport, 11(8): 1781-1783. [doi:10.1097/00001756-200006050-00037]

Hebb, A.O., Hebb, K., Ramachandran, A.C., et al., 2003. Glial cell line-derived neurotrophic factor-supplemented hibernation of fetal ventral mesencephalic neurons for transplantation in Parkinson disease: long-term storage. $J$. Neurosurg., 98(5):1078-1083. [doi:10.3171/jns.2003.98. 5.1078]

Heckmann, L., Fiedler, J., Mattes, T., et al., 2008. Interactive effects of growth factors and three-dimensional scaffolds on multipotent mesenchymal stromal cells. Biotechnol. Appl. Biochem., 49(3):185-194. [doi:10.1042/BA20070071]

Hidalgo-Figueroa, M., Bonilla, S., Gutierrez, F., et al., 2012. GDNF is predominantly expressed in the PV+ neostriatal interneuronal ensemble in normal mouse and after injury of the nigrostriatal pathway. J. Neurosci., 32(3):864-872. [doi:10.1523/JNEUROSCI.2693-11.2012]

Hisaoka, K., Maeda, N., Tsuchioka, M., et al., 2008. Antidepressants induce acute CREB phosphorylation and CREmediated gene expression in glial cells: a possible contribution to GDNF production. Brain Res., 1196: 53-58. [doi:10.1016/j.brainres.2007.12.019]

Lang, A.E., Gill, S., Patel, N.K., et al., 2006. Randomized controlled trial of intraputamenal glial cell line-derived neurotrophic factor infusion in Parkinson disease. Ann. Neurol., 59(3):459-466. [doi:10.1002/ana.20737]

Li, Z., Cui, Z., 2014. Three-dimensional perfused cell culture. Biotechnol. Adv., 32(2):243-254. [doi:10.1016/j.biotech adv.2013.10.006]

Lo, W.C., Hsu, C.H., Wu, A.T., et al., 2008. A novel cell-based therapy for contusion spinal cord injury using GDNFdelivering $\mathrm{NIH}_{3} \mathrm{~T}_{3}$ cells with dual reporter genes monitored by molecular imaging. J. Nucl. Med., 49(9): 1512-1519. [doi:10.2967/jnumed.108.051896]

Matsushita, Y., Nakajima, K., Tohyama, Y., et al., 2008. Activation of microglia by endotoxin suppresses the secretion of glial cell line-derived neurotrophic factor (GDNF) through the action of protein kinase $\mathrm{c} \alpha(\mathrm{PKC} \alpha)$ and mitogen-activated protein kinases (MAPKs). J. Neurosci. Res., 86(9):1959-1971. [doi:10.1002/jnr.21657]

Minnich, J.E., Mann, S.L., Stock, M., et al., 2010. Glial cell line-derived neurotrophic factor (GDNF) gene delivery protects cortical neurons from dying following a traumatic brain injury. Restor. Neurol. Neurosci., 28(3): 293-309. [doi:10.3233/RNN-2010-0528]

Nielsen, J., Gotfryd, K., Li, S., et al., 2009. Role of glial cell line-derived neurotrophic factor (GDNF)-neural cell adhesion molecule (NCAM) interactions in induction of neurite outgrowth and identification of a binding site for ncam in the heel region of GDNF. J. Neurosci., 29(36): 
11360-11376. [doi:10.1523/JNEUROSCI.3239-09.2009]

Ortiz-Ortiz, M.A., Moran, J.M., Ruiz-Mesa, L.M., et al., 2011. Protective effect of the glial cell line-derived neurotrophic factor (GDNF) on human mesencephalic neuron-derived cells against neurotoxicity induced by paraquat. Environ. Toxicol. Pharmacol., 31(1):129-136. [doi:10.1016/j.etap. 2010.09.013]

Parsadanian, A., Pan, Y., Li, W., et al., 2006. Astrocyte-derived transgene GDNF promotes complete and long-term survival of adult facial motoneurons following avulsion and differentially regulates the expression of transcription factors of AP-1 and ATF/CREB families. Exp. Neurol., 200(1):26-37. [doi:10.1016/j.expneurol.2006.01.014]

Patel, N.K., Bunnage, M., Plaha, P., et al., 2005. Intraputamenal infusion of glial cell line-derived neurotrophic factor in PD: a two-year outcome study. Ann. Neurol., 57(2):298-302. [doi:10.1002/ana.20374]

Sale, P., de Pandis, M.F., Vimercati, S.L., et al., 2013. The relation between Parkinson's disease and ageing. Comparison of the gait patterns of young Parkinson's disease subjects with healthy elderly subjects. Eur. J. Phys. Rehabil. Med., 49(2):161-167.

Schenck, M., Borgermann, C., vom Dorp, F., et al., 2007. Proapoptotic antibodies as new anticancer drugs. Der Urologe, 46(9):1262-1265 (in German). [doi:10.1007/ s00120-007-1385-7]

Shingo, T., Date, I., Yoshida, H., et al., 2002. Neuroprotective and restorative effects of intrastriatal grafting of encapsulated GDNF-producing cells in a rat model of Parkinson's disease. J. Neurosci. Res., 69(6):946-954. [doi:10.1002/jnr.10375]

Sun, M., Kong, L., Wang, X., et al., 2005. Comparison of the capability of GDNF, BDNF, or both, to protect nigrostriatal neurons in a rat model of Parkinson's disease. Brain Res., 1052(2):119-129. [doi:10.1016/j.brainres.2005.05.072]
Tanaka, Y., Ogasawara, T., Asawa, Y., et al., 2008. Growth factor contents of autologous human sera prepared by different production methods and their biological effects on chondrocytes. Cell Biol. Int., 32(5):505-514. [doi:10. 1016/j.cellbi.2007.12.012]

Tokutake, T., Ishikawa, A., Yoshimura, N., et al., 2014. Clinical and neuroimaging features of patient with early-onset Parkinson's disease with dementia carrying SNCA p.G51d mutation. Parkinsonism Relat. Disord., 20(2): 262-264. [doi:10.1016/j.parkreldis.2013.11.008]

von Frenckell, C., Malaise, M.G., 2012. Targeted therapy in inflammatory disease: cytokines. Rev. Med. Liege., 67: 22-28.

Wu, X., Chen, P.S., Dallas, S., et al., 2008. Histone deacetylase inhibitors up-regulate astrocyte GDNF and BDNF gene transcription and protect dopaminergic neurons. Int. J. Neuropsychopharmacol., 11(8):1123-1134. [doi:10.1017/ S1461145708009024]

Yasuhara, T., Shingo, T., Muraoka, K., et al., 2005. Early transplantation of an encapsulated glial cell line-derived neurotrophic factor-producing cell demonstrating strong neuroprotective effects in a rat model of Parkinson disease. J. Neurosurg., 102(1):80-89. [doi:10.3171/jns. 2005.102.1.0080]

Yasuhara, T., Shingo, T., Date, I., 2007. Glial cell line-derived neurotrophic factor (GDNF) therapy for Parkinson's disease. Acta Med. Okayama, 61(2):51-56.

Zesiewicz, T.A., Sullivan, K.L., Hauser, R.A., 2007. Levodopa-induced dyskinesia in Parkinson's disease: epidemiology, etiology, and treatment. Curr. Neurol. Neurosci. Rep., 7(4):302-310. [doi:10.1007/s11910-0070046-y]

Zuo, D.Q., Cai, Z.D., 2013. Progress in three-dimensional cell culture techniques and its application in bone tumor research. Chin. J. Oncol., 35(9):641-644 (in Chinese).

\section{中文概要：}

\section{本文题目：氧化锆陶瓷泡沫：一种有望大规模生产 GDNF 的生物支持材料}

Zirconium oxide ceramic foam: a promising supporting biomaterial for massive production of glial cell line-derived neurotrophic factor

研究目的：探讨氧化锆陶瓷泡沫细胞培养体系在胶质细胞源性神经营养因子（GDNF）生产方面的潜在用途。

创新要点: 运用氧化锆陶瓷泡沫构建神经胶质细胞 3D 培养体系并测定该体系, 该体系 GDNF 的产量明显优于 传统的细胞培养体系。

研究方法: 将原代神经胶质细胞种植于氧化锆陶瓷泡沫 3D 培养体系中, 采用四唑盐（MTT）比色法对其生物 相容性进行观察; 采用扫描电子显微镜观察该体系神经胶质细胞形态; 检测 DNA 含量以评估细胞 增殖情况; 采用酶联免疫吸附测定法 (ELISA) 检测该体系 GDNF 的产量; 采用实时定量聚合酶链 式反应（PCR）及免疫印迹试验（Western blotting）对胶质细胞中产生 GDNF 的信号通路激活情况 进行观察。

重要结论: 氧化锆陶瓷泡沫生物相容性好, 由其构建的 3D 培养体系的 GDNF 产量明显优于传统 2D 培养体系。

关键词组: 氧化锆; 陶瓷泡沫; 帕金森病 